working hours system (6 males, 2 females), variable working hour system (1 male, 1 female), discretionary work system (1 female), and retired employee and full-time housewives (2 males, 3 females). Among 11 workers, five of six mood statuses were significantly improved after the short-version climatotherapy. Furthermore, the items concerning job stress as:

1. heavy work responsibility,

2. absence of the advisers in the workplace,

3. anxiety for the outlook of workplace's future,

4. heavy workload,

5. bad physical environments in the workplace, and

6. bad interpersonal relationship, were highly correlated with a improvement of negative mood statuses by climatotherapy.

Conclusion These results suggest our short-version climatotherapy programme would be an effective measure to counter the mental health problem among workers.

\section{ASSESSMENT OF MENTAL HEALTH AND PERCEPTIONS AMONG PHYSICIANS OF A SECONDARY LEVEL GOVERNMENT HOSPITAL IN INDIA}

\footnotetext{
1,2Jitendra Kumar Meena*, ${ }^{2}$ Bratati Banarjee. 'Geetanjali Medical College and Hospital,
} Udaipur, Rajasthan, India; ${ }^{2}$ Maulana Azad Medical College, New Delhi, India

\subsection{6/oemed-2018-ICOHabstracts. 1600}

Introduction Several studies have suggested that doctors are more likely to be affected by psychiatric and related illnesses owing to multiple stressors like- busy work schedule, role conflicts, unhealthy life style and poor social life etc in them. Poor mental health among doctors is detrimental to existing health care system.

Methods A cross-sectional study was conducted secondary level hospital in north-west district of national capital region (NCR). All 89 doctors working in the Hospital were encouraged to participate. Global mental health assessment tool primary care version (GMHAT-PC) was used for conducting interviews. It is a validated and extensively used computer based tool for making a quick, convenient and comprehensive standardised mental health assessment. Prior consent was taken from each of study subject and confidentiality was maintained. Data was analysed using SPSS-17 version.

Result Mean age and job duration of the participants was $31.2 \pm 4.6$ and $7.5 \pm 3.4$ years. Participants had high prevalence of various psychiatric illnesses like- Anxiety-64\%, Depression $32 \%$, Personality disorders 22\%, Obsessive compulsive disorder $18 \%$. Alcohol intake and Drug abuse was present in $38 \%$ and $12 \%$ of participants respectively etc. Significant association was found between age and years of work with presence of mental illness $(p=0.04),(p=0.01)$. Among the doctors interviewed $42.6 \%$ believed that they are susceptible to mental disorders. Only $21.3 \%$ found themselves capable enough in diagnosis and $17.9 \%$ in management of mental disorders. About $71.9 \%$ participants felt the need of training in basic mental health screening and management.

Discussion The current cross-sectional study reflects high burden of psychiatric problems viz. anxiety, depression and alcohol consumption among doctors. There is a high demand for a basic training in identification and management of mental illnesses for health professionals and need for mental health promotion.

\section{WORK STRESS, SHIFTWORK AND MENTAL WELL-BEING AMONG RUSSIAN PROFESSIONAL DRIVERS}

1,2Bashkireva Angelika*. 'Gerontological Centre of Leningrad Region, St. Petersburg, Russia; ${ }^{2}$ Research and Innovation Centre "Professional Longevity», St. Petersburg, Russia

\subsection{6/oemed-2018-ICOHabstracts. 1601}

Introduction Mental well-being is the main element in neurobehavioral status of the drivers' organism that determine the efficiency and reliability of his professional activity. Psychic adaptation in the system 'Driver - vehicle - traffic environment' is considered to be a process, which provides the optimal accordance between a person and environment during the driving. This study was designed to estimate the psychoemotional status (PES), to compare the prevalence of psychoadaptive disorders among professional lorry-drivers in connexion with their age, occupational hazards, work schedule and driving experience.

Methods 150 professional lorry-drivers (men aged 30-59 years) were examined using a clinical questionnaire to identify, estimate and compare neurotic states according to 6 scales of anxiety, neurotic depression, asthenia, hysterical type of reacting, obsessive-phobic disorders and neurovegetative disturbances.

Results The study comprised drivers with stable psychic adaptation (58\% of those under study), drivers with unstable psychic adaptation - a risk group (34\%), and drivers with stable psychic disadaptation, i.e. with borderline mental disorders (BMD) $-8 \%$, respectively. The predominance of drivers with unstable psychic adaptation and BMD was found: $\chi^{2}(2)=7.45$, $\mathrm{p}<0.05$. As factor-disperse analysis showed the variability of psychoemotional imbalance levels in lorry-drivers was found to be due to a combination of the following factors: occupational exposure $(\mathrm{F}(2,12)=100.6, \mathrm{p}<0.001)$ and shiftwork ( $\mathrm{F}$ $(2,12)=34.16, p<0.001)$. Comparative analysis of psychoadaptive disorders revealed the prevalence of the asthenic symptoms $(\mathrm{F}(1)=10.503, \mathrm{p}<0.01)$, anxious and depressive manifestations $(\mathrm{F}(1)=7.509, \mathrm{p}<0.01)$, hysterical reactions $(\mathrm{F}(1)$ $=6.040, \mathrm{p}<0.05)$ among professional lorry-drivers.

Conclusion The presented results showed the occupational hazards and long driving experience being the risk factors for the development of psychic disadaptation and BMD among professional lorry-drivers. The applied parameters of PES and early manifestations of BMD are informative criteria for assessing the mental well-being, life quality and professional suitability of lorry-drivers.

\section{IMPACT OF MENTAL ILLNESS ON PRODUCTIVITY OF THE MOBILE WORKFORCE AS THE WORKER PROFILE TRANSITIONS FROM BABY BOOMER TO MILLENNIAL}

Robert L Quigley*, Myles Druckman, Jules Duval. International Corporate Health Leadership Council, Trevose, USA

\subsection{6/oemed-2018-ICOHabstracts. 1602}

Introduction The International Corporate Health Leadership Council (ichlc.org) is a non-profit foundation comprised of medical directors of global corporations representing virtually all industry sectors. The Council reviews the latest health trends relevant to global enterprise and provides key recommendations so appropriate standards are benchmarked and best practices identified. One such recent trend is the increase, to epidemic proportions, of mental illness within the mobile 